\title{
6
}

\section{PHOTOGRAPHY AGAINST THE ANTHROPOCENE}

\section{The anthotype as a call for action}

\author{
Kristof Vrancken
}

The online digital photo archive grows daily at an increasing pace. Contributing to the digital visual overload are not only the thousands of selfies or hundreds of sunsets that are uploaded every second, but also the automated images created by security cameras, satellites, and Google Streetview. Almost every moment and street corner is digitally captured, documented, and shared (Shore 2014, 7-11). This digital hyper-documented world raises a question: how can photography still be useful and how can an image maker can bring his or her message across?

Disciplines like photography and film attempt to respond to this digital dominance, and are experiencing a growing suspicion of the digital process. It cannot be denied that the digital revolution is a tremendous step forward in terms of speed, quality, and convenience. It has changed our way of seeing, thinking, and acting enormously, but now that digital technology has become so firmly embedded in our lives it is perhaps time to consider what we have lost.

This sense of loss is acknowledged by a recently established group of artists, photographers, and filmmakers, whom Jonathan Openshaw describes as postdigital artisans (2015, 7-9). They use digital technology, but also fall back on old techniques and examine how they can combine these to arrive at a new and modern version of the profession. They are looking for something that digital technology cannot offer, namely tactility and authenticity: the feel of the material, the experience, the magical moment when craftsmanship and non-reproducibility develop something unique. This is not so much a nostalgic vision of history as a critical stance towards the digital era.

Regarding photography from this perspective made me doubt the evidence of my own predominantly digital work process and prompted me to look for alternatives. I have experienced the transition from analogue to digital personally during my studies. I therefore see myself as part of what Openshaw calls the “connector generation" $(2015,9)$. This means that, like many other contemporary 
image makers, I combine different styles, methods, and media: photographing with analogue large and medium format cameras, developing negatives with alternative methods, scanning, experimenting with emulsions, old procedures, $360^{\circ}$ recording techniques, video, digital image recordings, and processing. This opens up a range of possibilities, both on a technical and a content level. I feel that an image maker today must almost necessarily examine cross-disciplinary methods in order to revive photography and make it useful again. These experiments strengthen the message of the photographic image to communicate in an innovative visual way that prevents the image from sinking away into the everyday, fleeting, visual digital mush (Shore 2014).

\section{Dark ecology}

In an online world in which truths and untruths are intertwined, in which main affairs and additional ones cannot be separated and in which the fight for attention usually is more important than the message, it is difficult to reach a mass audience (Rushkoff 2015). There are, however, stories that require our supreme attention. One story that urgently needs to be told and retold, is that of the human era, or how humanity became a geological force. How we increasingly pressured the earth and nature and how we therefore urgently need to redefine our thinking and acting to keep the planet liveable for future generations (Bonneuil and Frezoz 2017).

In contemporary academic literature this story is usually referred to as the Anthropocene or the Capitalocene. The discussion about which terminology is most suitable, and what the starting point of this era would be, is ongoing (Haraway 2016; Moore 2016). Apart from this theoretical discourse we should however be afraid of the consequences and weirdness of climate change, writes Timothy Morton in his book Dark Ecology (2016). We should be standing on the barricades to call for structural action to limit the unforeseen effects of the

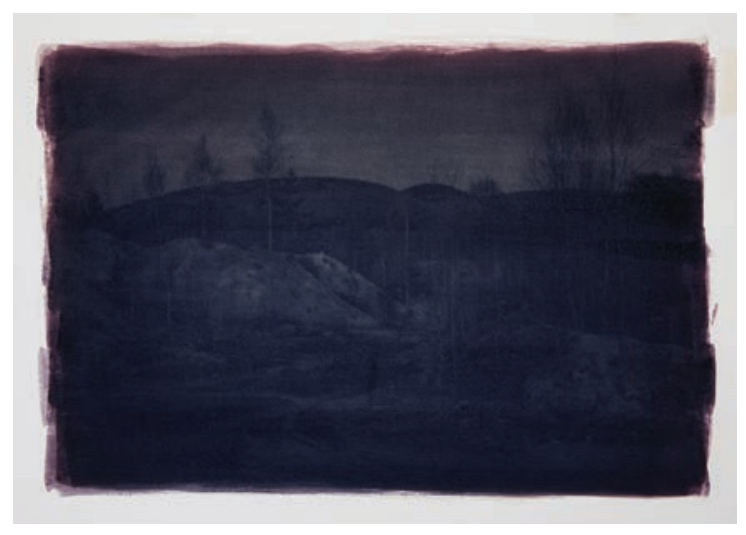

FIGURE 6.1 Transit, slag heaps of Winterslag, Genk, 2017. (Kristof Vrancken) 
destruction of ecosystems, mass extension, and growing social inequality. All too often, however, we click away and continue to lead our lives as if nothing is going on and the cited problems will resolve themselves. Proponents of the Degrowth movement have been urging for some time now for a gradual transition toward a reduced or at least smarter consumption, to the construction of a society that is alert to the imbalance between human and planet and which is not solely directed to short-sighted economic growth margins and power relations (D'Alissa, Demaria and Kallis 2014).

If we don't act now, the ecological reality will soon overtake us. We are at a point of no return for the survival of our species and life on earth. Politicians, scientists, philosophers, historians, and artists - and in fact everyone - should dare to bet on a new narrative and vision. We too quickly lose sight of the urgent current problems, the complexity of big stories and their mutual cohesion because we constantly want to be entertained by easily to understand digital distraction, determined by our likes (Rushkoff 2015). We need action and awareness in addition to academic discourse. According to Bonneuil and Frezoz, this means freeing ourselves from repressive institutions and from alienating dominations and imaginaries. (2017, 288-291). T. J. Demos asks how we can convert into image and narrative the disasters that are slow moving and long in the making, disasters that are attritional and of indifferent interest to the sensational driven technologies of our image-world $(2017,13)$. One of his conclusions is that more activism, not neutrality, is needed: "We need a revolt against brutality against the violence of climate change" $(2017,81)$. There is an urgent need for a global call to action.

\section{Call for action}

My artistic PhD research, carried out at the LUCA School of Arts, responds to this call in an unconventional, visual manner. To shape the vital transformation to a sustainable world we need new streams of thought and design processes, as well as a new visual language in order to understand, document, and spread them. My research is based on the methodology of Sustainist Design. This is a recent movement within social critical design that argues in favour of sustainable design processes. In Sustainist Design Guide (2013) Schwarz and Krabbendam define four pillars for sustainable design. The first is Sharing - exchanging knowledge, materials and tools, both online and offline, instead of hiding them, leads to greater efficiency in development and production. The second pillar, Localism, stands for returning to and upgrading the local. Our focus should be locally rooted but globally connected. The third pillar, Connectedness, exceeds the principle of sharing in development and manufacturing. It underlines the importance of offline and online interpersonal contact. This pillar also refers to the connection with nature and argues in favour of restoring our bond with it. Finally, Proportionality stands for bringing production into balance and introduces custom designing to suit the social and local context. Proportionality also incorporates the aspect of time. In a world in which everything must go faster it is a relief to build in slowness. By daring to 
stand still there is more time to discover and to reflect. Sustainist design no longer designs for a society; it starts a new movement from within.

Central to my research are the following questions: What effect does applying sustainist design principles in the photographic process have on visual language, method, material use, and photographic techniques? This interdisciplinary approach creates a new hybrid method of visual storytelling in which not only the image is important but also the process, context, and social interaction. In addition to the relationship with design, my research questions photography as a discipline. By analysing and opening up the entire photographic process new lines of reasoning about forming and experiencing images arise. The anthotype image is a key tool in this process.

\section{The anthotype process}

Regarding photography from the perspective of postdigital artisans, dark ecology and sustainist design prompted me to return to the roots of the discipline, which are located in the middle of the nineteenth century, the same period as one of the turning points of the Anthropocene.

The anthotype is a traditionally analogue process. This photographic technique was first described by the prominent scientist, mathematician, botanist, and experimental photographer Sir John Herschel (1792-1871) in 1842. Herschel's significance in the development of photography is incalculable. He invented a way to fix photographic images using hyposulfite, which is still used today. He also discovered the cyanotype process, in which the print eventually becomes cyanogen, and worked closely together with the well-known pioneer Henry Fox Talbot (1800-1877) on the first negative-positive process (Batchen 2016; James 2016). The anthotype process is an organic contact printing process that affects the discolouration of natural pigments exposed to ultraviolet light (James 2016). An anthotype is created by applying a photosensitive emulsion made from the colour pigments of plants to a carrier and exposing it to sunlight for several days or weeks. Ultraviolet rays break down the colours, slowly creating an image. The organic emulsion undergoes a chemical change or photo-destruction during this process and the pigments become lighter. Not only does each plant respond differently to light, the harvesting point, freshness, pollution, and additives are also parameters that affect the discolouration.

In order to extract the colour of plants the organic fibres must first be crushed. Adding alcohol is sometimes necessary to help plants to give off their chlorophyll pigments to the liquid. The emulsion can be applied to all kinds of surfaces. Every surface will change the look of the print and emphasizes the handmade characteristics of the process. When the coating is dry the carrier is ready to be illuminated. Most photographic techniques require a negative that gives a positive image after illumination, as was the case with Herschel's and Talbot's photographic experiments. The anthotype process, however, requires a positive. It can either be an analogue positive (glass plate or film) or a digital one (transparent). To illuminate 
the image it must be placed in sunlight. Ultraviolet rays break down the colours, slowly creating an image by selective destruction of the colour pigments. The unexposed parts of the image will retain their colour, while the exposed parts will slowly lose their colour and intensity.

The plurality of the anthotype printing process proved to be endless. Each plant responds differently to light, and the harvesting point, freshness and additives also affect the discolouration. ${ }^{1}$ Light sensitivity can vary greatly from plant to plant, even within the same species. For example, my experiments with a poppy emulsion showed some results after only a few days, while the exposure time of blackberries took a few weeks or even months. I did some tests by using an anthotype sheet in a large format camera to expose it directly in the camera, but after an exposure time of more than two months in full summer there was no visible result. For the time being, the possibilities of the anthotype process seem limited to contact printing.

Since pigments of vegetable origin are used the landscape forms an essential factor in creating an anthotype. Not only does it provide the setting for the photographic image, it also provides the ingredients for the photographic emulsion that is used to print the image. Even the an sich invisible aspect of the photographed landscape, the soil composition, plays an important role because it partially determines which plants grow in that specific spot and therefore which pigments can be used for the photographic emulsion. Moreover, a combination of the soil composition and external environmental conditions, such as the quantity of sunlight that the plant receives and the air-soil contamination, has an impact on the chemical composition and, consequently, on the progress of photosynthesis (Ahmad 2002).

I experienced first hand how much our society is accustomed to speed when it comes to obtaining results during my initial experiments with the anthotype technique. It required a lot of patience and a completely different approach than that of a solely digital recording. Collection of materials, preparation of emulsion, coating of paper and development of prints turned out to be time-consuming activities.

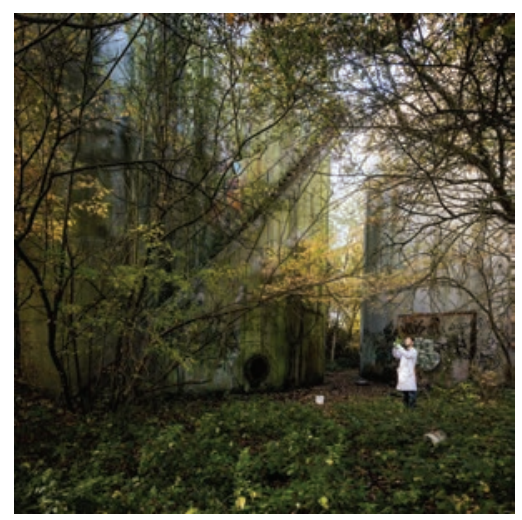

FIGURE 6.2 Harvesting ingredients on a contaminated area, 2016. (Kristof Vrancken) 
FIGURE 6.3 Cameraless photograph: dune pansy, abandoned Ford grounds, 2016. (Kristof Vrancken)

I literally had to follow the pace of the seasons and had to adapt my agenda to the harvest times of the different plants. The entire process also came to a halt in winter due to a lack of materials and sunlight. It made me realize how little we actually know about these plants and how our lives have become disconnected from nature (Rushkoff 2015, 66-129). ${ }^{2}$

The anthotype print is saturated with time, much more so than the fleeting digital image. Not only does it require time to make the photographic emulsion, but the time that the print must be exposed to sunlight depends upon the light sensitivity of the species. Once the anthotype print is formed the time aspect continues to play a role. Although each anthotype is unique - only one print can be made - it is at the same time ever-changing. ${ }^{3}$ If the print is exposed to light it will continue to fade. This has interesting consequences. Because the anthotype image fades over time it does not necessarily have to be seen as a static image with a limited shelf-life. Its constant degradation can also be interpreted as a slowly moving image. The contours of what was photographed are not permanent, and after some time has passed the original image also transforms. Recent tests I performed in a simulated lab environment as part of the exhibition The Artist's Studio in Z33 - House of Contemporary Art, have shown that an anthotype print with an emulsion of elderberry and alcohol needs more than 130,000 lux hours to form a well-exposed image. ${ }^{4}$ Further tests will be undertaken in my studio to investigate the relationship between the appearance and reappearance of an anthotype image. When placed on a timeline, the inherent gradient of the print adds a valuable and meaningful element to the anthotype image: entropy as an essential part of the photographic work.

Due to the temporary aspect of the image, the imperfections, the amount of work involved and the long exposure times, this procedure never became popular. ${ }^{5}$ Yet, for me, this transitoriness is precisely where the poetry and power of the image lie. It is precisely the aforementioned characteristics that make the anthotype 

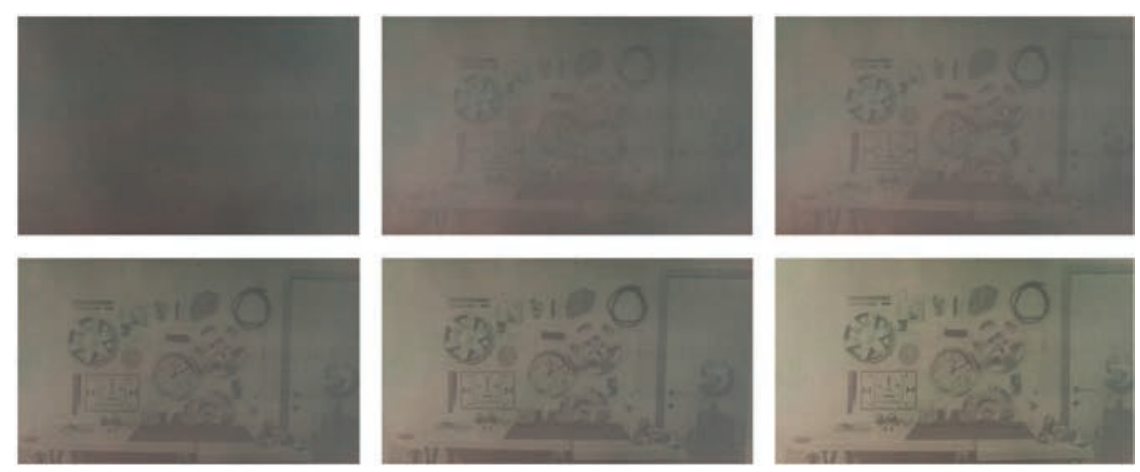

FIGURE 6.4 The appearance of an anthotype print - lab test, 2018. (Kristof Vrancken)

process relevant today, as a counter reaction to the sterile digital image. It forms a critical counterbalance against the current obsession with the eternally enduring or an unnatural denial of the ephemeral (Rushkoff 2015, 159).

The vulnerable side of the anthotype image is also closely connected to its tactility. Contrary to the fleeting digital image, which can often only be seen on a computer screen and is not always printed (Openshaw 2015, 4-9), an anthotype cannot exist without a physical medium. This essential physical existence, combined with the fact that the print was made with an emulsion of vegetable origin, emphasizes how much this type of image is linked to the tangible world and, above all, to nature. Its tactility renews attention on experiencing photographic images. While digital photos only serve the eye, an anthotype also appeals to one's sense of smell (the image smells like the plants that were used) and sense of touch (small plant fibres are often visible and perceptible). Even one's sense of taste can be involved when the emulsion is drunk by the viewers. ${ }^{6}$

The anthotype print has a final and very special property related to this connection with nature. By actually using plants originating from the depicted landscape to create the photographs, an interesting relation is established between the physical landscape and its photographic representation. The anthotype print not only represents the landscape, it is the landscape since it is made from the flora that grows there. The multisensory organic and tactile anthotype image that carries the landscape within itself is a response against today's Anthropocene visualizations which are mainly dominated by scientifically framed imagery, digital high resolution images and data visualization (Demos 2017, 13).

The time aspect, the entropy, the tactility, the connection with nature, the importance of the experience and the ability to incorporate what was photographed in the print, enable the anthotype to open up a number of layers of meaning that remain irrevocably closed to digital photography. Because plants are increasingly affected by environmental stresses, especially by the devastating consequences of pollution and global climate change (Ahmad, et al., 2002), the anthotype, in which plants are used in the preparation of a photographic emulsion, acts as a suitable tool 
to illustrate the narrative of the Anthropocene. The technique is also a means of raising awareness of it and of reacting against it. One of the oldest photographic methods becomes paradoxically an appropriate instrument for approaching a contemporary topic and to relive history. I would like to illustrate this on the basis of two artistic projects: Transit and MijnKOOL.

\section{Transit}

The project Transit started in 2016. It resulted from a collaboration with the C-Mine Cultural Centre, the Emile Van Doren Museum, and the City of Genk, Belgium. ${ }^{7}$ The main focus of this photographic series is the history and evolution of the landscape of the former mining city Genk in Belgium.

The waves of change in Genk, currently the third largest industrial city in Flanders, can be unmistakably linked to the pre-industrial era and the effects of two Industrial Revolutions. The history of Genk illustrates on a micro-scale the development of the Anthropocene. The area around the city changed drastically, from a wide-open landscape loved by late nineteenth-century painters such as the Brussels artist Emile Van Doren (1865-1949), to an industrial city. Van Doren fell in love with the idyllic landscape, marked by infertile sandy areas, vast heathlands with ponds, and marshland (Figure 6.6). He gathered a group of artists around him who painted the landscape extensively in open air. In imitation of the Barbizon school of painters in France, the Genk school of painters became one of the most important artist colonies in Belgium around 1900. In 1901 André Dumont (1847-1920) found coal in the Genk area, and large-scale coal exploitation started in 1917 (Reulens 2015).

Emile Van Doren was sad to see the industrialization of Genk and in his paintings hung on to the romantic landscapes, in which he completely ignored the emerging mining industry. In some panoramic views, he eliminated mine shafts and dumping grounds to not disturb the romantic quality (Reulens 2015). Armand Maclot (1877-1959), on the other hand, took a more activist stance and sketched an ominous view of a mining landscape suffocated by smoke plumes, with the ironic title Villégiature or refuge (Reulens 2010).

The artists based around Genk, and especially Van Doren and Maclot, played an important political role in the fight for nature conservation. They, for instance, opposed for a long time the construction of roads and industry in their beloved area around the steel ponds. In the beginning of the twentieth century there were, thus, already active counter voices that felt the necessity to protect ecosystems and nature. Unfortunately, economic interests prevailed. Because of the flourishing coal industry - at its peak there were as many as three coal mines in Genk - pollution increased as well. In the 1960s and 1980s coal exploitation was no longer a profitable industry and the mines closed down one by one, leaving their marks on a radically transformed landscape (Reulens 2010).

The city proceeded to attract other industries. For example, car manufacturer Ford - historically seen as the founder of standardized mass production with 


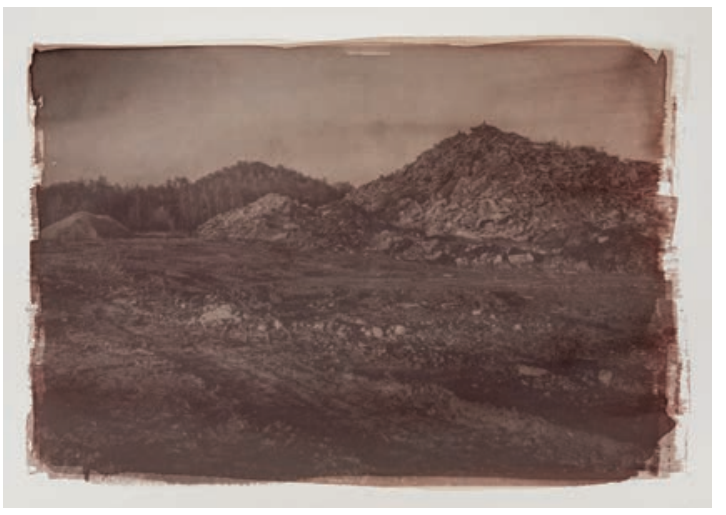

FIGURE 6.5 Transit, slag heap of Zwartberg (black-mountain), Genk, 2017. (Kristof Vrancken)

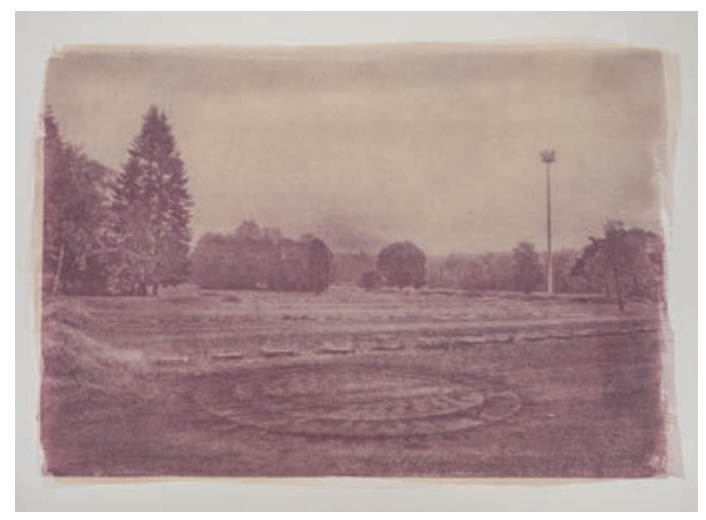

FIGURE 6.6 Transit, slag heap of Waterschei and parking lot, Genk, 2017. (Kristof Vrancken)

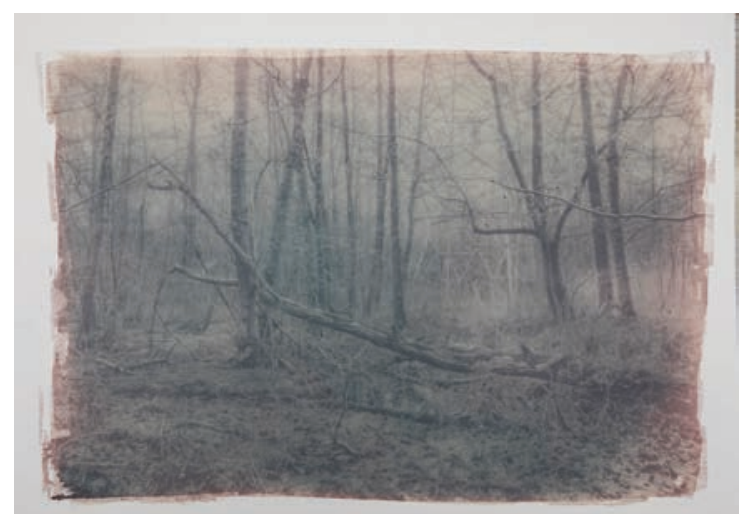

FIGURE 6.7 Transit, Waterschei, Genk, 2017. (Kristof Vrancken) 
assembly lines (Bonneuil and Frezoz 2017, 229) - established a factory in 1964 that was shut down permanently in 2015. At its peak the factory made almost half a million cars each year and employed over 14,000 people (Kloostermans 2014). After the closure, the company sold its grounds to Genk for a symbolic one euro. The costs involved with cleaning up the polluted site, however, were estimated at 12 million euros (Figure 6.10) (Lenaerts 2015). The establishment of metalprocessing companies and other heavy industrial branches brought economic development to Genk but it also had severe ecological consequences. A study into internal exposure to pollutants and their early effects in 14- to 15-year-olds in the period 2007 to 2011 showed that young people from South Genk, where the industrial estates are located, had higher concentrations of heavy metals and polycyclic aromatic hydrocarbons in their bodies. Higher levels of DNA damage and hormonal disturbances, which increase the chance of developing cancers, were also detected (Vrijens et al. 2014).

The city of Genk has worked hard to reduce pollution but a lot of work still needs to be done. The city is currently making efforts in nature conservation. Although the population of Genk grew to 66,000 inhabitants it is still one of the greenest regional cities in Belgium. Heathlands are being maintained, burned, and levelled to restore a piece of the authentic - albeit cultivated by human hands landscape. The endless and undisturbed horizon that appealed so strongly to Emile Van Doren has, however, been lost for good. Chimneys, steel constructions, apartment buildings or windmills always come into view.

For Transit I made a series of artistic work portraying Genk's landscape using the anthotype method, looking in 2017 for the muse found there by Emile Van Doren. The title Transit refers both to the many evolutions - from nature to industry - that the landscape of the mining town of Genk has undergone since the introduction of the first Industrial Revolution, as well as to the type of van which was manufactured in the Genk Ford factory between 1960 and 2000.

Each image is about how human action cultivates the landscape and how this landscape yields to it or resists (Notteboom 2013). The Genk landscape changes so fast that it almost sits in a continuous transition. It happened more than once during the preparation of this project that a location that was to be photographed had disappeared on arrival. Geographically and via Google Earth it would still exist, but it had in reality been transformed into an unrecognizable, churned, almost surreal place. Often these areas are waiting for a new destination in the contemporary economic reality. Sand is supplemented and taken away. ${ }^{8}$ Roads are constructed to be deserted. Woods are planted while others are wiped away. Buildings are constructed on the dumping grounds of the mines. The landscape is continually managed while the landscapes that for the moment are unmanaged are most attractive to me.

I used plants from the area that I photographed to display Genk's biodiversity and soil quality to create my anthotypes. In doing so, the landscape is not only captured on camera but it is also literally incorporated and preserved in the print. In this 
way, the print, in fact, becomes a physical piece of Genk. The choice of a plant to make an emulsion is, thus, not based on some coincidence, but declares something about the history and the current state of the photographed location.

The series Transit comprises 11 anthotype prints made from different kinds of plants that grew at the photographed locations. A greenhouse was built next to the Emile Van Doren Museum to be able to expose the different images and to enable the prints to be exposed all summer long despite the changeable rainy Belgian weather. The month of August 2017 had relatively few sunny hours, which caused problems for the print production. The prints based on poppy were exposed in about two weeks, while the elderberry emulsion needed an exposure time of three to four weeks, just like the emulsion based on marigold. As earlier tests had already shown, the emulsion based on blackberry was the least light-sensitive. Some prints needed an exposure time of at least 8 weeks.

Plants are not only capable of generating an image. Research proves that some plants are excellent receptors and collectors of heavy metals and fine dust, and that anomalies in growth and flowering of certain plants in a certain area could be an indicator of pollution. Therefore, they are not only extremely suitable as research tools in exact sciences, but also in my work. Because these plants collect these toxic substances in their systems, these also end up in the anthotype prints. ${ }^{9}$ The traces of pollution are literally encapsulated in the print. This causes the anthotypes of the polluted landscapes of Genk to have a disturbing undertone, despite their romantic appearance.

The Anthropocene is a difficult and abstract concept. It could easily remain invisible to the general public until it is too late to act. The consequences of a global ecological catastrophe happen too slowly for our human perception even though they become more and more apparent. The delay between cause and effect of our human activity on this earth is too large in order for us to see the big picture. Morton therefore sees the Anthropocene as a hyper-object, something that

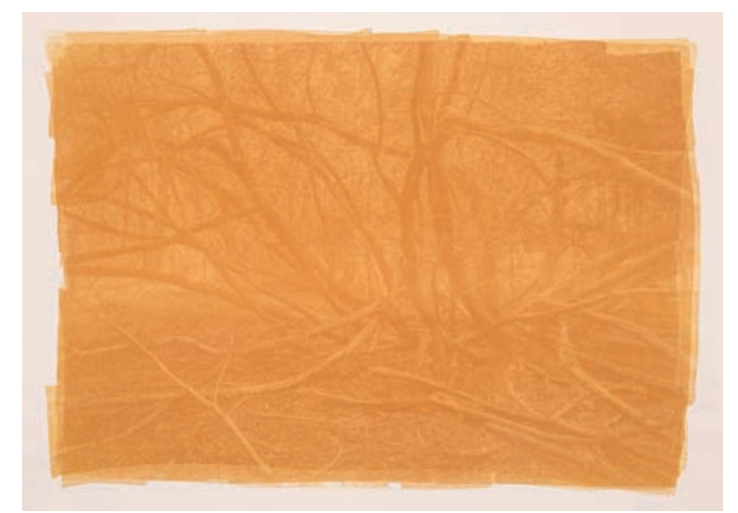

FIGURE 6.8 Transit, Genk-South, 2017. (Kristof Vrancken) 


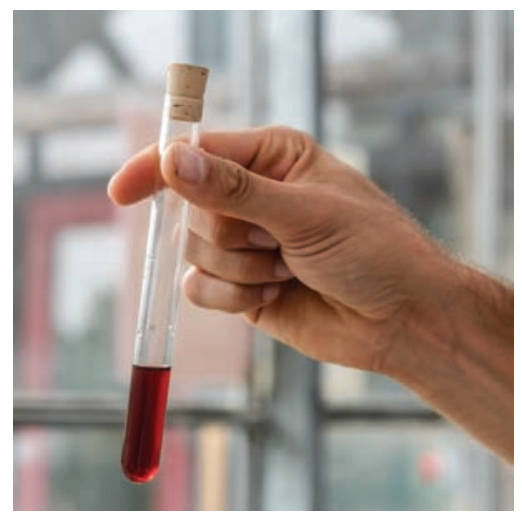

FIGURE 6.9 The potable and light-sensitive Anthropocene elixir. (Kristof Vrancken)

stretches out endlessly in time and space, making it impossible to fathom (2016, 47-49). I think that we need to make the problematic of the Anthropocene more apparent and personal in order to bring the message across.

In an attempt to make the Anthropocene more tangible, I created for the Transit series, in addition to the photographic prints based on the anthotype process, a drinkable photographic emulsion based on the plants in the documented polluted areas. For the creation of this emulsion I followed historical liquor and anthotype recipes by Sir John Herschel. With this knowledge in hands I created a somewhat sinister, organic, photographic emulsion that was both light-sensitive and nice, both sweet and wry.

The sanguineous elixir is made on the basis of sloe berries and elderberries, harvested on the seriously polluted sites of the closed Ford factory at Genk. The berries can contain increased levels of nickel, chrome, manganese, and zinc, but the potion itself tastes deliciously sweet as these metal parts are as good as odourless and tasteless. They don't impact on the taste and thus can enter unnoticed into our system on a daily basis. We are not conscious of the fact that we daily absorb harmful substances by driving in heavy traffic in the morning, living in busy cities alongside industrial areas and consuming food polluted by pesticides and antibiotics. But consciously drinking this toxic emulsion makes you an active bearer of the Anthropocene. The elixir reveals things we don't see, and possibly also don't want to see. Drinking this 'unheimliches' elixir thus almost becomes a political act.

I presented the Anthropocene elixir and the photographic images for the first time during the A-Z Night \#5: Dark Ecology, Artistic Encounters in the Anthropocene organized by Z33 House of Contemporary Art. ${ }^{10}$ I toasted to the Anthropocene and to my surprise most of the audience emptied their glass. There were only a few that resolutely refused to do so, but the hesitation that was palpable in the room before and after the toast was a sign that the elixir definitely caused an intrinsic unrest and that the Anthropocene is hard to digest. According to Benjamin Verdonck, the most constructive thing to do as an artist is to take the 


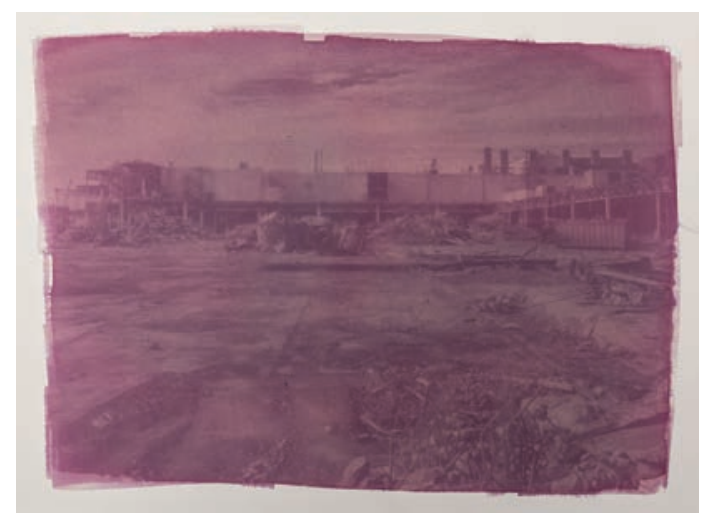

FIGURE 6.10 Transit, abandoned Ford grounds, Genk, 2017. (Kristof Vrancken)

darkest elements from reality, transform them into an object or a performance and enter into a dialogue with an audience.

The sweet taste of the dark elixir mirrors the call to give in to the lure of laziness, doing nothing, and continuing our lifestyles and the current consumption model. Luxury and abundance after all taste sweet. The pollution is a free addition. Degrowth, although essential to tackle the consequences of climate change and pollution, tastes rather wry. Or as Morton puts it eloquently: "Dark Ecology is ecological awareness, dark depressing. Yet ecological awareness is also dark-uncanny, and strangely it is dark-sweet" $(2016,18)$. Ironically, Morton refused to drink this dark emulsion when I offered it to him during a brief encounter in Nijmegen on the occasion of his talk about his book Being Ecologic in January 2018.

Translating the different layers of meaning of an image - from an impression of a forever-lost pristine landscape to pressured ecosystems due to industrial superiority - would not have been possible with a digital picture. The literal and figurative multi-layeredness could only be achieved through the anthotype process. This shows how one of the oldest photographical techniques is, ironically, better able to visually communicate the urgency of a contemporary topic than more recent ones.

\section{MijnKOOL (myCABBAGE)}

Next to the artistic series Transit, there is a second track in this Genk project that involves a partnership with design studio SOCIAL MATTER. ${ }^{11}$ In order to stimulate awareness about the Anthropocene on a larger scale we organized several workshops with local Genk residents. In these workshops, we shared the anthotype process and the opportunity to relive the wonder of this historical photographic process. The main ingredient for the photographic emulsion was in this case red cabbage. Thanks to its anthocyanins, red cabbage could function as a bio-indicator and proved to be an interesting ingredient in the anthotype process (Chalker-Scott 
1999; Szczygłowska et al. 2011). If red cabbage is grown in pure soil it will turn out more blue, and in alkaline environments it will turn more green and yellow. If the red cabbage is grown in acidic soil, it will yield a red colour. An erratic $\mathrm{pH}$ value can point to contamination. I carried out two experiments to test this method in May 2016 and 2017. A dozen cabbage plants were planted in contaminated and uncontaminated areas in Genk, and in pure potting soil (Figure 6.14). Four months later the cabbage pants were harvested and documented. Although some plants had trouble surviving due to the city's poor subsoils, shortage of rain and damage from caterpillars and slugs, there was enough basic material to carry out $\mathrm{pH}$ tests. For this test I added three grams from each red cabbage plant to $50 \mathrm{ml}$ distilled water and brought it to the boil in order to dissolve the anthocyanins in water. This resulted in clearly perceptible colour differences in the final liquids, varying from light to dark blue and from light to dark purple. The diverse colours in the test tubes show that red cabbage really does react to the $\mathrm{pH}$ value and soil quality of the subsoil that it grows in. At the same time, my test illustrates and confirms that this method is suitable for making a visual map of the diverse, historically formed soil compositions of an area. ${ }^{12}$

Every participant in the mijnKOOL workshop received a red cabbage plant grown in pure compost and was asked to plant it in his or her garden. After a few months the group came together again and brought their harvest. The participants used their plant to create an emulsion that would serve as a basis for their anthotype portrait and their print of the planting area. Everyone had to follow the protocol as strictly as possible in order for the experiment to succeed. Each participant made an emulsion by weighing $100 \mathrm{~g}$ of leaves of their red cabbage and boiling it for 30 minutes in $400 \mathrm{ml}$ of distilled water. In order not to affect the test results alcohol was not added to the photographic emulsion. Depending on the acidity of the soil in which the cabbage was grown the final prints clearly showed different colours, bringing forth a participative sample card of the Genk surface - and thanks to the anthotype process - of the subsurface as well.

A map of the City of Genk was created to illustrate this. It was made with organic ink from local raw materials and drawn by illustrator Jenny Stieglitz. The map consists of two layers. On the lower layer the soil samples of the different locations are resting in small petri dishes which allow you to discover the diverse soil structures of Genk. On the higher layer you can find the different emulsions made by the participants that are clearly different in colour. By comparing the colour of the anthotypes with those of the emulsions you can find the growing place of the cabbage on the map.

In the context of MijnKOOL I also experimented with red cabbage to develop photographic films. During one of the workshops I made portraits of the participants using my analogue large format camera. I used a Sinar F2 with a Rodenstock $150 \mathrm{~mm}$ lens with a maximum aperture of $\mathrm{f} / 5.6$ and a copal shutter. This camera was made by Swiss camera manufacturer Sinar in 1986 and was as an advanced modular lightweight professional large format field view camera. I usually use this camera to photograph landscapes. The slow, fully manual method of handling the 
camera results in a more thought-out image strategy, but photographing a portrait with a large format camera is an experience in itself. Not only for the photographer but also for the person portrayed. The workshop turned out into a historical reenactment instead of a standard portrait shoot. The participants reacted with amazement about the use of this old analogue camera. Young children looked with disbelief at the large strange device where the image on the frosted glass is swapped left-right and displayed the other way around. The fact that the image was not immediately visible also caused astonishment among the youngest participants. Due to the large film format of $4 \times 5$ inches, there is little depth of field and manual focusing therefore needs to be done with extreme precision. It takes five to ten minutes to fully prepare the camera for recording, which is an eternity in today's digital age. Unlike photographing a landscape, it is not only the photographer who has to concentrate on large-format shooting, but also the person portrayed who needs the necessary concentration not to move. A small movement to the back and the head disappears from the sharpness plane. Due to the slowness of the entire photographic process, both the photographer and the person portrayed become more aware of every small gesture and the tension is built up. The 'click' of the Sinar Copal shutter is loud and fills the entire space with one clear stroke. The negative is exposed, the photographer and the person portrayed breathe again. "Can I have a look at the picture?" one man asked.

The photographic large format film was not developed using the standard chemical products of industrial manufacturers, but with a self-made developer of red cabbage juice, vitamin $\mathrm{C}$ and soda. To develop my $4 \times 5$ inch Ilford FP4 film I used $32 \mathrm{~g}$ of water-free soda, $10 \mathrm{~g}$ of pure vitamin $\mathrm{C}$ and the juice of $400 \mathrm{~g}$ of red cabbage in a solution of $600 \mathrm{ml}$ distilled water. I got the best results with a developing time of 15 minutes at a temperature of $23^{\circ} \mathrm{C}$. This process - related to the caffenol process - considerably reduces the quantity of harmful chemicals normally used during the photographic development (Williams 1995; Bendandi 2015). ${ }^{13}$ Not only can red cabbage develop negative film, but it also causes a shift of contrasts which makes the image harsher and less even than a traditionally developed image. The negatives developed with red cabbage juice formed the basis of the anthotype prints that the participants of the workshops made with the emulsion of their home-grown red cabbage

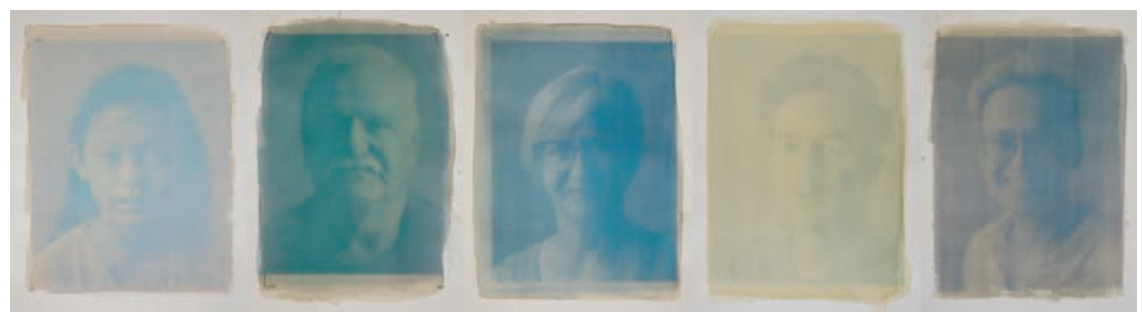

FIGURE 6.11 Portraits mijnKOOL, Genk, 2017. (Kristof Vrancken) 


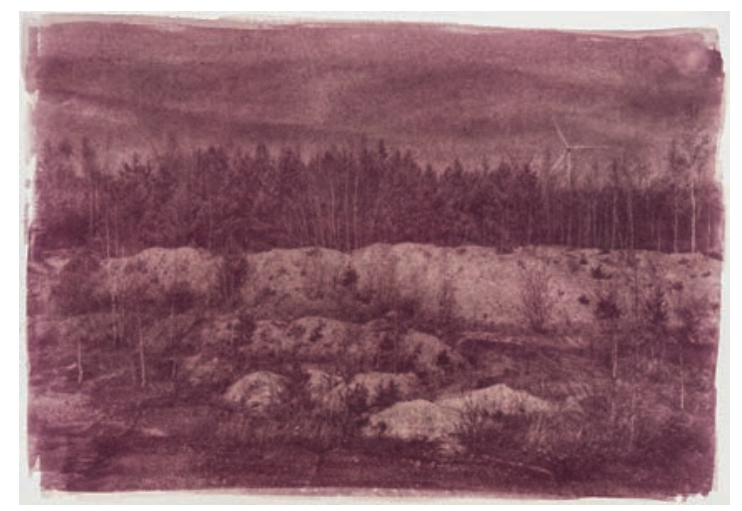

FIGURE 6.12 Transit, Winterslag, Genk, 2017. (Kristof Vrancken)

MijnKOOL, the title of this participatory project, alludes, on the one hand, to the red cabbage plants that participants grew in their own gardens. On the other hand, it alludes to Genk's industrial past via the words 'mine' and 'coal'. By adopting the anthotype process as a participatory research method, we intended to bring people together through open communication and to raise awareness about the unbalanced human-nature ratio. The anthotype technique was effectively used as a call for action as inhabitants of Genk were informed via the workshops about the potential uses of wild plants, soil quality and local problems with pollution. They were directly addressed because they and their habitat were implicated and united in the photographic process and the final image. This participatory method provided a strong local context as well as a wider reach. The project not only connected the usual photography and culture enthusiasts, but also engaged a wider network of participants. Combining knowledge and strategies from exact sciences, social design, history, and photography in a transdisciplinary project thus created new possibilities to inform and activate people. At the same time it enabled them to relive and experience the magic and possibilities of historical photographic processes.

\section{Conclusion}

My research shows that it is important to explore the possibilities of old techniques in the light of contemporary and future technologies. Media archaeology can thus play a crucial role in developing ways to visually capture the world and society in a meaningful way and to also understand them better. In my search to make the problem of the Anthropocene visible and contribute to a greater consciousness of the problematic state of our planet, I deliberately chose to use the nineteenth-century anthotype technique in artistic photography as a participatory research method. The application of this method is not purely an aesthetic 
choice. The organic anthotype technique has special characteristics that are in danger of being lost in the digital era, such as incorporating time, entropy, and tactility, the connection with the landscape and nature, and the importance of sensory perception. As the photographic emulsions for the anthotypes are plantbased they not only form a good indicator of the state of the increasingly disturbed and polluted landscape in which the plants have to survive, but they also incorporate this information as critique in the photographic image. The ability to embed what was photographed in the print itself is almost impossible in digital photography. One of the oldest photographic techniques thus becomes one of the most appropriate tools to visually and multisensorial translate the urgency of a current topic and to call for much needed action. At the same time it also allows us to relive photographic history through experimentation and, in combination with today's digital technologies, opens up new possibilities and avenues of thought in imaging. ${ }^{14}$

\section{Notes}

1 Steve J. Appleyard (2012) Experimenting with Cameraless Photography using Turmeric and Borax: an Introduction to Photophysics. Physics Education, 47(4): 423-428.

2 "Most of us today live in cities and spent most of our time indoors, where the cues that used to alert us to the changing days, moon phases and seasons are largely hidden from us". About our contemporary digital culture and alienation from the seasons (Rushkoff 2015, 107).

3 This uniqueness of an anthotype image is reminiscent of Walter Benjamin's aura of a not mechanically reproduced work of art: "This unique existence of the work of art determined the history to which it was subject throughout the time of its existence. This includes the changes which it may have suffered in physical condition over the years [...]" (Wells 2003, 43).

4 See my project Latency Hasselt 2018, http://kristof-vrancken.com/project/latency

5 Over the last few years, there has been increased interest in the technique thanks to the remarkable qualities of the anthotype. The work of Christine Elfman and Binh Danh illustrate this evolution (James 2016, 43, 50, 56-59).

6 See my project Manufactuur Hasselt in 2016, http://www.sustainistgaze.com/tag/hasselt/.

7 See http://www.c-minecultuurcentrum.be/; http://www.emilevandorenmuseum.be/.

8 For instance, I found seashells in a vast sand plain in South Genk at more than $200 \mathrm{~km}$ distance from the coast. This infertile layer of sand caused the withering of many of the trees.

9 At the same time, some plants can also be used to clean grounds. This method is called phytoremediation. The research group of Environmental Biology of the University of Hasselt had poplars planted on the Ford grounds in Genk that can partially break down the present oil pollution (Barac et al. 2009).

10 See: http://www.a-znights.be/event/a-z-night-5/

11 SOCIAL MATTER, founded by Giacomo Piovan, is looking for ways to return abandoned and polluted industrial areas to the local population by means of social and participating design. See http://www.socialmatter.eu/.

12 Further scientific research, however, will have to show the level of concentrations of heavy metals that nest within the photographic emulsions made from the red cabbages and in the final anthotype image and/or whether there are actual colour differences between the emulsions of polluted and non-polluted plant species. With the results, we could make a visual mapping of the possible pollution and quality of the soil. After completing this Genk project I would like to apply this methodology to other cities and polluted sites. 
13 This open-source developing process was developed in 1995 by Scott A. Williams at the Rochester Institute of Technology. Caffenol is a developer made of coffee, vitamin C and soda. See < https://people.rit.edu/andpph/text-coffee.html> [Accessed 11 November 2017].

14 I would like to thank Jan Boelen, Dr Leen Engelen, Dr Leen Kelchtermans, Prof Dr Jean Manca, Dr Dirk Reynders, Dr Veerle Van der Sluys and Prof Dr Roland Valcke for their valuable remarks and Edith Doove for the translation.

\section{Bibliography}

Ahmad, P. (ed.) (2002) Environmental Adaptations and Stress Tolerance of Plants in the Era of Climate Change. New York: Springer.

Barac, T., Weysens, N., Oeyen, L., et al. (2009) Field Note: Hydraulic Containment of a Btex Plume using Poplar Trees. International Journal of Phytoremediation, 11(5): 416-424.

Batchen, G. (2016) Emanations. The Art of the Cameraless Photograph. Munich, London and New York: DelMonico Books-Prestel.

Bendandi, L. (ed.) (2015) Experimental Photography. A Handbook of Techniques. London: Thames and Hudson.

Bonneuil, C. and Fressoz, J.B. (2017) The Shock of the Anthropocene: The Earth, History and Us, Translated from French by David Fernbach. London: Verso.

Chalker-Scott, L. (1999) Environmental Significance of Anthocyanins in Plant Stress Responses. Photochemistry and Photobiology, 70(1): 1-9.

D’Alissa, G., Demaria, F. and Kallis, G. (2014) Degrowth: A Vocabulary for a New Era. London and New York: Routledge.

Demos, T.J. (2017) Against the Anthropocene: Visual Culture and Environment today. Berlin: Sternberg Press.

Hallmann, C.A., Sorg, M., Jongejans, E., et al. (2017) More than 75 Percent Decline over 27 Years in Total Flying Insect Biomass in Protected Areas. Plos One, [e-journal] 12(10). https://doi.org/10.1371/journal.pone.0185809.

Haraway, D.J. (2016) Staying with the Trouble: Making Kin in the Chthulucene. Durham: Duke University Press.

Herschel, J. (1842) On the Action of the Rays of the Solar Spectrum on Vegetable Colours, and on Some New Photographic Processes. Philosophical Transactions of the Royal Society of London, 132: 181-214.

James, C. (2016) The Book of Alternative Photographic Processes. Boston: Cengage learning.

Kloostermans, G. (2014) Einde van een tijdperk. Het Belang van Limburg, 9 Nov., p. 4.

Lenaerts, X. (2015) Sanering vervuild Fordterrein kost Vlaamse regering 12 miljoen euro. Het Laatste Nieuws, 15 Oct., p. 17.

Moore, J.W. (2016) Anthroposcene or Capitalocene? Nature, History and the Crisis of Capitalism. Oakland, CA: PM Press/Karios.

Morton, T. (2016) Dark Ecology. For a Logic of Future Coexistence. New York: Columbia University Press.

Notteboom, B. (2013) Drie keer de mijnstreek. In: K. Reulens and D. Lauwaert, ed. 2013. Citygraphy \#03. Brussel: Eferma. 31-45.

Openshaw, J. (2015) Post Digital Artistans, Craftmanship with a New Aesthetic in Fashion, Art, Design and Architecture. Amsterdam: Frame Publishers.

Reinold, G., Overs, M., Roberts, E., et al. (2012) The Caffenol Cookbook and Bible. [pdf] Baden-Württemberg: Community Spirit Publications. Available at: $<$ http://caffenolcookbook.com> [Accessed 11 November 2017].

Reulens, K. (2010) Genk door schildersogen. Landschapsschilders in de Limburgse Kempen, 1850-1950. Leuven: Davidsfonds. 
Reulens, K. and Lauwaert, D. (eds) (2013) Citygraphy \#03. Brussels: Eferma.

Reulens, K. (2015) Emile Van Doren (1865-1949). Biografie van een schilder en zijn landschap. Oostkamp: Stichting Kunstboek.

Ripple, W.J., Wolf, C., Newsome, T.M., et al. (2017) World Scientists' Warning to Humanity: A Second Notice. BioScience, [e-journal], bix125. https://doi.org/10.1093/ biosci/bix125.

Rushkoff, D. (2014) Present Shock: When Everything Happens Now. New York: Current.

Schwarz, M. and Krabbendam, D. (2013) Sustainist Design Guide: How Sharing, Localism, Connectedness and Proportionality are creating a New Agenda for Social Design. Amsterdam: BIS Publishers.

Shore, R. (2014) Post Photography. The artist with a Camera. London: Laurence King Publishing Ltd.

Szczygłowska, M., Piekarska, A., Konieczka, P., et al. (2011) Use of Brassica Plants in the Phytoremediation and Biofumigation Processes. International Journal of Molecular Sciences, 12(11): 7760-7771.

Vanhellemont, M., Verheyen, K., Staelens, J. and Hermy, M. (2009) Factors Affecting Radial Growth of the Invasive Prunus Serotina in Pine Plantations in Flanders. European Journal of Forest Research, 129: 367-375.

Vrijens, J., Leermakers, M., Stalpaert, M., et al. (2014) Trace Metal Concentrations Measured in Blood and Urine of Adolescents in Flanders, Belgium: Reference Population and Case Studies Genk-Zuid and Menen. International Journal of Hygiene and Environmental Health, 4(5): 515-527.

Wells, L. (2003) The Photography Reader. London and New York: Routledge.

Williams, S. (1995) A Use for that Last Cup of Coffee: Film and Paper Development. [online] Imaging and Photographic Technology Department, School of Photographic Arts and Sciences, Rochester Institute of Technology. Available at: <https://people.rit.edu/ andpph/text-coffee.html> [Accessed 11 November 2017]. 